\title{
Development And Evaluation of Anti- Inflammatory Herbal Formulation
}

\author{
${ }^{1}$ Chavhan A. Sarin, ${ }^{2}$ Gupta N. Hrishikesh, ${ }^{3}$ Shinde A. Sushil kumar, ${ }^{4}$ Phandade V. Govind \\ Govt. College of Pharmacy, Kathora Naka Road, Amravati-444604, Maharashtra, India
}

\begin{abstract}
:
Herbal remedies are more acceptable in the view that they are safe with fewer side effects than the synthetic ones. Herbal formulations have more demanded in the market. Inflammatory diseases including different types of rheumatic diseases are major cause of morbidity of the working force throughout the world. This has been called the 'King of human miseries'. The present work deals with the Development and Evaluation of Poly-Herbal Anti-inflammatory Formulation containing alcoholic extract of Vitex negundo leaves, Boswellia serrata, Berberis aristata \& wintergreen oil. The gel was prepared using polymer carbopol 940 $(1 \% \mathrm{w} / \mathrm{v})$, propylene glycol 400, triethanolamine, propyl paraben, methyl paraben and required amount of distilled water. Various conc. of extract were taken for formulations (F1 to F3). Prepared formulations (F1 to F3) were evaluated for various parameters like colour, appearance, consistency, viscocity, $\mathrm{pH}$, spreadability, stability along with anti-inflammatory activity by using model carageenan induce paw edema in rats. F3 formulation was found optimum for all the parameter.
\end{abstract}

Key words: Vitex negundo, Boswellia serrata, spreadability, pH, carbopol.

\section{INTRODUCTION:}

Inflammation and rheumatism remain serious problems in the present era. Inflammation is a complex immune response to vascular tissues injury or infection caused by pathogens, clinically characterized by signs of swelling, redness, pain, warmth and loss of function. ${ }^{[1]}$

Inflammation is an important feature of great number of diseases. It is a response of the tissue to an injury, infection, irritation or foreign substance. It is a part of host defence, but when the response becomes too great it may be far worse than the disease itself and in extreme conditions, it may be fatal. Antiinflammatory drugs are considered important because of their wide therapeutic potential and their utility in a number of diseases such as arthritis, lupus erythematosus, pemphigus and rheumatic fever and in a number of other disorders associated with pain, pyrexia and inflammation.

Many anti-inflammatory drugs (both NSAIDs and corticosteroids) have been developed but their safety profile studies have shown that none of them is clearly safe. They show wide ranges of adverse effects. Due to adverse reactions of synthetic and chemical medicines being observed round the globe, herbal medicines have made a comeback to improve our basic health needs. Many plants and herbs such as ginger, turmeric, olive oil, have been shown to exhibit potent anti-inflammatory effect ${ }^{[2]}$.

Vitex nigundo linn. Vitex negundo L. commonly known as Nirgundi belongs to family Verbenaceae. Vitex negundo Linn. use for cure various types diseases. Traditionally the leaves of are documented to possess antibacterial, antitumor, astringent, febrifuge, sedative, tonic and vermifuge. This species is globally distributed in Indo-Malesia, cultivated in America, Europe, Asia and West Indies. Within India, it is found throughout the Maharashtra ${ }^{[3]}$. Vitex contains the flavonoids, casticin, chryso-splenol and vitexin. Vitex contains Chrysophenol D. which is a substance with anti-histamine properties and muscle relaxant. Leaves contains two alkaloids nishindine and hydrocotylene. The main compounds are viridiflorol (19.55\%), betacaryophyllene $(16.59 \%)$, sabinene $(12.07 \%)^{[5]}$.

Boswellia serrata Boswellia serrata Roxb. is one of the medicinal plants of Burseraceae family. This herb is mentioned in traditional Unani texts as an effective remedy for bronchitis, asthma, cough, cardiovascular 
diseases, diarrhea, dysentery, ringworm, boils, fevers (antipyretic), skin and blood diseases, mouth sores, vaginal discharges, etc. It chiefly possesses anti-arthritic, anti-inflammatory, anti-hyperlipidemic, anticancer, hypoglycemic, anti-asthmatic, analgesic, hepato-protective etc. ${ }^{[4]}$

Alcoholic extract of salai guggal was reported to posses anti-inflammatory and anti- arthritic activities in animals which were due to boswellic acids, which are pentacyclic triterpenes. Boswellic acids selectively inhibit leucotriene synthesis by inhibiting 5-LOX in an enzyme directed, non-redox, and non-competitive mechanism ${ }^{[5]}$.

Berberis aristata The Plant Berberis aristata DC. belongs to family Berberidaceae, known as Indian barberry in English and Daruhaldi in Hindi. Berberine has demonstrated wide range of pharmacological activities including; antihypertensive, anti-inflammatory, antioxidant, antidepressant, anticancer, antidiarrhoeal, cholagouge, hepatoprotective and above all, antimicrobial. Recent studies, have thrown light on antidiabetic and hypolipidemic activities of the alkaloid. Berberine has been tested clinically in the treatment of oriental sore, diarrhea, trachoma diabetes mellitus type-2, hypercholesterolemia, and congestive cardiac failure ${ }^{[6]}$.

The aim of current research trend is to discover newer drugs from plant kingdom which may provide therapeutic cure and which also should be cost effective, thus would be widely accepted developing nation like India.

Material and method: Carbopol 940, Propylene glycol 400 (LOBA CHEMIE PVT.LTD, Mumbai); Propyl paraben, Methyl Paraben, EDTA (Research- Lab Fine Chem Industries, Mumbai); Triethanolamine (SAMAR CHEMICALS, Nagpur) All other chemicals used were of analytical grade.

- Plant material collection and authentification: The leaves of Vitex negundo collected from local area of Amravati and the leaves of Boswellia serrata collected from local area of Wari (Maharashtra) in August 2015. The gum resin of plant Boswellia serrata and the roots of plant Berberis aristata were purchased from Barsaiya Ayurvedic Shop, Amrawati. The above herbs were authentified by Dr. S. N. Malode, head of botany department, Govt. Vidarbha Institute of Science and Humanities, Amravati, Voucher specimens and sample material was deposited in the Pharmacognosy \& Phytochemistry Laboratory, Govt. College of Pharmacy, Amravati.

- Extract preparation: The collected materials were washed thoroughly in water, chopped, air dried for a week at $35-40^{\circ} \mathrm{C}$ and pulverized in electric grinder and exhaustively extracted successively in soxhlet apparatus, using petroleum ether, ethanol respectively. Boswellia serrata extracted by maceration process in which gum resins were soaked in petrolium ether upto 2 days and then marc again extracted by using solvent ethanol, macerate upto 2 days ${ }^{[7,8]}$. The extracts were concentrated under reduced pressure.

Formulation of Gel:Carbopol $940(1 \% \mathrm{w} / \mathrm{w})$ and purified water were taken in a beaker and allowed to soak for $24 \mathrm{hr}$. Stirred by mechanical stirrer at 400 to $650 \mathrm{rpm}$. Add ethanolic extract Vitex negundo, Boswellia serrata and Berberis aristata of were dispersed in alcohol in separate container then add this in carbopol 940. Then neutralized with sufficient quantity of Triethanolamine. Propylene glycols 400 as penetration enhancer, methyl paraben and Propyl paraben as preservatives were added slowly with continuous gently stirring until the homogenous gel was formed. The formulation of developed gel formula given in table no. 1 .

\begin{tabular}{|c|c|c|c|}
\hline Ingredient & F1 & F2 & F3 \\
\hline Ethanolic extract of Vitex negundo & $100 \mathrm{mg}$ & $150 \mathrm{mg}$ & $200 \mathrm{mg}$ \\
\hline Ethanolic extract of Boswellia serrata & $100 \mathrm{mg}$ & $150 \mathrm{mg}$ & $200 \mathrm{mg}$ \\
\hline Ethanolic extract of Berberis aristata & $50 \mathrm{mg}$ & $50 \mathrm{mg}$ & $50 \mathrm{mg}$ \\
\hline Carbopol 940 & $1 \mathrm{gm}$ & $1 \mathrm{gm}$ & $1 \mathrm{gm}$ \\
\hline Alcohol & $2 \mathrm{ml}$ & $2 \mathrm{ml}$ & $2 \mathrm{ml}$ \\
\hline Methyl paraben & $0.2 \mathrm{gm}$ & $0.2 \mathrm{gm}$ & $0.2 \mathrm{gm}$ \\
\hline Propyl paraben & $0.02 \mathrm{gm}$ & $0.02 \mathrm{gm}$ & $0.02 \mathrm{gm}$ \\
\hline EDTA & $0.01 \mathrm{gm}$ & $0.01 \mathrm{gm}$ & $0.01 \mathrm{gm}$ \\
\hline
\end{tabular}


Chavhan A. Sarin ${ }^{1}$, International Journal of Ayurvedic \& Herbal Medicine 7(4) July.-Aug. 2017 (2756-2762)

\begin{tabular}{|c|c|c|c|}
\hline Propylene glycol 400 & $4 \mathrm{ml}$ & $4 \mathrm{ml}$ & $4 \mathrm{ml}$ \\
\hline Wintergreen oil & $2 \mathrm{ml}$ & $2 \mathrm{ml}$ & $2 \mathrm{ml}$ \\
\hline Triethanolamine (To maintain $\mathrm{pH} 7$ ) & Q.S. & Q.S. & Q.S. \\
\hline Water & $100 \mathrm{ml}$ & $100 \mathrm{ml}$ & $100 \mathrm{ml}$ \\
\hline
\end{tabular}

Table 1: Formulation table showing composition of F1, F2 and F3 gel formulation

\section{EVALUATION OF DEVELOPED GEL FORMULATION ${ }^{[9]}$}

Following are the parameters for the evaluation of gel as per standard guidelines.

1. Physicochemical parameters: All the formulated herbal gels for inflammation were tested for the physiochemical parameters like appearance, colour, odour, homogenicity by visual inspection and the result are shown in Table no. 2

\begin{tabular}{|l|l|l|l|l|}
\hline Formulations & \multicolumn{1}{|c|}{ Appearance } & \multicolumn{1}{c|}{ Colour } & \multicolumn{1}{c|}{ Odour } & \multicolumn{1}{c|}{ Homogeneity } \\
\hline I & Smooth & Pale yellow & Characteristic & Homogenous \\
\hline II & Smooth & Dull Green & Characteristic & Homogenous \\
\hline III & Smooth & Yellowish green & Characteristic & Homogenous \\
\hline
\end{tabular}

Table 2 : Physicochemical Parameters

2. $\mathbf{p H}^{[10]}$ : Weighed $20 \mathrm{gm}$ of each gel formulation were transferred in $10 \mathrm{ml}$ of beaker and measured it by using digital $\mathrm{pH}$ meter i.e. Equip-Tronics. Formulation was carried out in triplicate and the average values are represented. $\mathrm{pH}$ of the topical gel formulation should be between 3-9 to treat the skin infection. The results are shown in Table no. 3

3. Spreadability ${ }^{[11]}$ : Spreadability was determined by the apparatus which consists of a wooden block, which was provided by a pulley at one end. By this method spreadability was measured on the basis of slip and drag characteristics of gels. An excess of gel (about $2.5 \mathrm{~g}$ ) under study was placed on the ground slide. The gel was then sandwiched between this slide and another glass slide having the dimension of fixed ground slide and provided with a hook. A $1 \mathrm{~kg}$ weight was placed at the top of the two slides for 5 minutes to expel air and to provide a uniform film of the gel between the slides. Excess of the gel was scrapped off from the edges. The top plate was then subjected to pull of $50 \mathrm{~g}$ with the help of string attached to the hook and the time (in seconds) required by the top slide to cover a distance of $5 \mathrm{~cm}$ was noted. A shorter interval indicated better spreadability. Spreadability was calculated using the following formula:

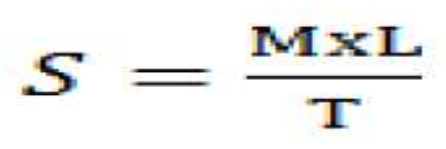

Where,

$\mathrm{S}=$ spreadability,

$\mathrm{L}=$ length of glass slide,

$\mathrm{M}=$ weight tied to upper slide and $\mathrm{T}=$ time

Viscosity: Viscosity of herbal gel was determined by using Brookfield rotational viscometer. The correct spindle was selected (spindle No. 4) for the given product then the operating condition was setup. Then the viscosity was measured directly at 6-rpm speed by keeping the torque constant. The mean was obtained. The viscosities of all formulations have been found to be in the centipoises at room temperature, and the results are shown in Table no. 3

The viscosity of gelling agents in the gelling layer be within range of about $1000 \mathrm{cps}$ to about 100,000cps. The viscosity is determined by following formula:

Viscosity (centipoises) $=$ Dial Reading $\times$ Factor

Factor: For model LV- 4(spindle) at 6 RPM is $1 \mathrm{M}(\mathrm{M}=1000)$ 
4. Extrudability ${ }^{[12]}$

The gel formulations were filled in standard capped collapsible aluminum tubes and sealed by crimping to the end. The weights of the tubes were recorded. The tubes were placed between two glass slides and were clamped. $500 \mathrm{gm}$ was placed over the slides and then the cap was removed. The amount of the extruded gel was collected and weighed. The percent of the extruded gel was calculated (>90\% extrudability: excellent, $>80 \%$ extrudability: good, $>70 \%$ extrudability: fair).

\section{Drug Content (Content of Uniformity) ${ }^{[13]}$ :}

The drug content was determined by taking $1 \mathrm{ml}$ of the formulation and diluting it to $100 \mathrm{ml}$ with distilled water. Aliquot of different concentration was prepared by withdrawing $1 \mathrm{ml}$ from above solution and further diluted to $10 \mathrm{ml}$ with phosphate buffer 7.4, Vitex negundo, Boswellia serrata and Berberis aristata was determined at $250 \mathrm{~nm}, 260 \mathrm{~nm}$ and $348 \mathrm{~nm}$ respectively by using UV-Vis spectrophotometer. The absorbance of other solutions also taken against blank solution by using respective $\lambda$ max (Shimadzu UV/VIS spectrophotometer-1700). The \% Drug content in all formulations was in the range of 40-85\% indicating uniform distribution of drug. It was calculated by using the equation, which was obtained by linear regression analysis of calibration curve. Drug content of three gel formulation given in table no. 3

Table 3: Results of evaluation parameters of various gel formulations

\begin{tabular}{|c|c|c|c|c|c|}
\hline Formulation & pH & $\begin{array}{c}\text { Spreadability } \\
\text { g.cm/sec }\end{array}$ & $\begin{array}{c}\text { viscosity at 6 rpm } \\
\text { (centipois) }\end{array}$ & \% Extrudation & \% Drug content \\
\hline I & 5.75 & 27.77 & 58666.6 & 70.04 & $82.6 \%$ \\
\hline II & 5.75 & 21.13 & 33000 & 71.81 & $92.1 \%$ \\
\hline III & 6.05 & 22.06 & 32666.6 & 76.89 & $92.8 \%$ \\
\hline
\end{tabular}

6. In-vitro drug release study ${ }^{[13]}$ :

The in-vitro diffusion studies were carried out using Franz diffusion cell apparatus and semi-permeable cellophane membrane. Cellophane membrane (egg membrane \& rat skin), previously soaked overnight in phosphate buffer 7.4 was mounted by tied and sandwiching between the donor and receiver compartment. Franz diffusion cell with a diameter $3.7 \mathrm{~cm}$ was used in in-vitro release studies. A glass tube with both end open, $10 \mathrm{~cm}$ height and $3.7 \mathrm{~cm}$ outer diameter was used as a permeation cell. A one gram sample was accurately weighed and placed on a semipermeable cellophane membrane to occupy a circle of $3.7 \mathrm{~cm}$ diameter. The loaded membrane was stretched over the lower open end of a glass tube of $3.7 \mathrm{~cm}$ diameter and made water tight by rubber band. The tube (donor compartment) was immersed in a beaker containing $100 \mathrm{ml}$ of phosphate buffer $\mathrm{pH} 7.4$ (receptor compartment). The cell was immersed to a depth of $1 \mathrm{~cm}$ below the surface of buffer. The system temperature was maintained at $37^{\circ} \pm 1^{\circ}$ and speed was maintained at $30 \mathrm{rpm}$ throughout the experiment by magnetic stirrer (Fig.2.2). Samples $5 \mathrm{ml}$ were withdrawn at intervals of 0, 1, 2, $3,4,5$ and 6 hour, the volume of each sample was replaced by the same volume of fresh buffer to maintain constant volume. The samples were filtered through Whatman filter paper, diluted up to $10 \mathrm{ml}$ and absorbance was taken by UV spectrophotometer at respective Kmax. The experiment was carried out triplicate and average value is reported.

\begin{tabular}{|c|c|c|c|}
\hline In vitro drug diffusion study time (hr) & F1 & F2 & F3 \\
\hline 0 & 0 & 0 & 0 \\
\hline 1 & 10.8 & 13.7 & 14.04 \\
\hline 2 & 13.7 & 25.5 & 27.85 \\
\hline 3 & 23.5 & 34.4 & 36.57 \\
\hline 4 & 31.9 & 46.9 & 48.71 \\
\hline 5 & 43 & 56.2 & 57.2 \\
\hline
\end{tabular}

Table no. 4: Diffussion study 
Chavhan A. Sarin ${ }^{1}$, International Journal of Ayurvedic \& Herbal Medicine 7(4) July.-Aug. 2017 (2756-2762)

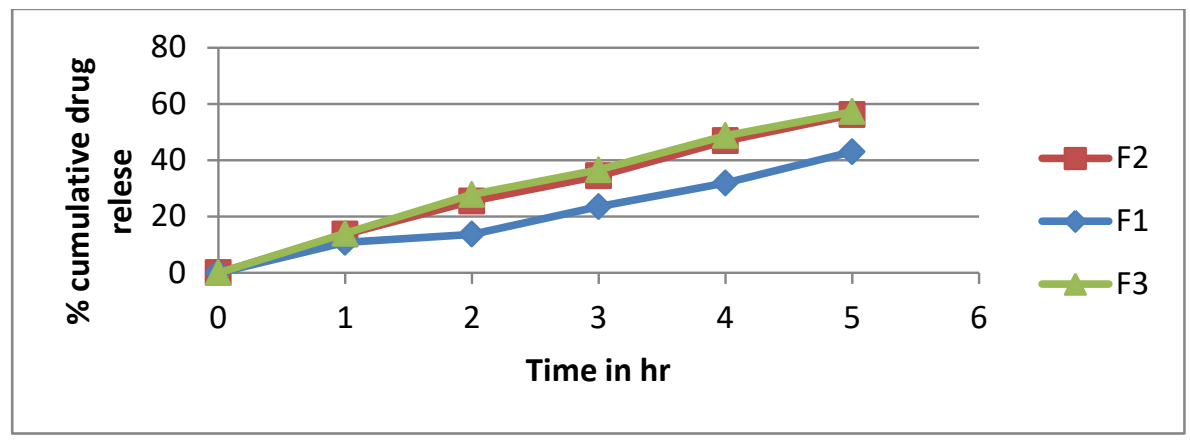

Figure 2 : Graphical representation of drug diffusion studies of gel formulations

7. Stability studies ${ }^{[13]}$

The stability study was performed as per ICH guidelines.The formulated gel was filled in collapsible tubes and stored at different temperatures and humidity viz,

1) $25^{\circ} \mathrm{C} \pm 2^{\circ} \mathrm{C} / 60 \% \mathrm{RH} \pm 5 \% \mathrm{RH}$

2) $30^{\circ} \mathrm{C} \pm 2^{\circ} \mathrm{C} / 65 \% \mathrm{RH} \pm 5 \% \mathrm{RH}$

3) $40^{\circ} \mathrm{C} \pm 2{ }^{\circ} \mathrm{C} / 75 \% \mathrm{RH} \pm 5 \% \mathrm{RH}$

Samples were evaluated for various criteria after 3 months. The tests carried out for the stability samples were appearance, $\mathrm{pH}$, drug content uniformity, spreadability, and extrudability. The methodology adopted for all the above mentioned studies was similar to procedure discussed previously.

\begin{tabular}{|c|c|c|c|}
\hline \multicolumn{4}{|l|}{ Colour } \\
\hline Formulation & At Room Temperature & At $40 \pm 2^{\circ} \mathrm{C} / 75 \pm 5 \%$ RH & Stored in freeze \\
\hline $\mathrm{I}$ & No change in Colour & Slight Change in colour & No change in Colour \\
\hline II & No change in Colour & Slight Change in colour & No change in Colour \\
\hline III & No change in Colour & Slight Change in colour & No change in Colour \\
\hline \multicolumn{4}{|c|}{ Phase Separation } \\
\hline Formulation & At Room Temperature & At $40 \pm 2{ }^{\circ} \mathrm{C} / 75 \pm 5 \% \mathrm{RH}$ & Stored in freeze \\
\hline $\mathbf{I}$ & $\begin{array}{l}\text { No Phase } \\
\text { Separation }\end{array}$ & $\begin{array}{l}\text { No Phase } \\
\text { Separation }\end{array}$ & $\begin{array}{l}\text { No Phase } \\
\text { Separation }\end{array}$ \\
\hline II & No Phase Separation & Slight Phase Separation & No Phase Separation \\
\hline III & No Phase Separation & No Phase Separation & No Phase Separation \\
\hline \multicolumn{4}{|l|}{$\mathbf{p H}$} \\
\hline Formulation & At Room Temperature & At $40 \pm 2^{\circ} \mathrm{C} / 75 \pm 5 \%$ RH & Stored in freeze \\
\hline $\mathbf{I}$ & 5.75 & 5.63 & 5.78 \\
\hline II & 5.75 & 5.24 & 5.09 \\
\hline III & 6.03 & 6.37 & 5.09 \\
\hline \multicolumn{4}{|c|}{ Viscosity at 6 rpm (centipoises) } \\
\hline Formulation & At Room Temperature & At $40 \pm 2^{\circ} \mathrm{C} / 75 \pm 5 \%$ RH & Stored in freeze \\
\hline I & 58666.6 & 66160 & 41660 \\
\hline II & 33000 & 57166 & 54160 \\
\hline III & 32666.6 & 33000 & 32000 \\
\hline \multicolumn{4}{|c|}{ Spreadability(g. cm/sec) } \\
\hline Formulation & At Room Temperature & At $40 \pm 2^{\circ} \mathrm{C} / 75 \pm 5 \%$ RH & Stored in freeze \\
\hline $\mathbf{I}$ & 27.77 & 31.77 & 29.05 \\
\hline II & 21.13 & 33.59 & 33.5 \\
\hline III & 22.06 & 27.77 & 27.06 \\
\hline
\end{tabular}

Table 5 : Stability study of herbal gel formulation 


\section{Result and discussion:}

All physiochemical evaluation parameter of gel formulation are given in Table no. 2 from the result evident that all three gel formulation having good gelling property and homogenicity. The $\mathrm{pH}$ of all three formulations ranged between 5.75 to 6.05 which is acceptable for topical formulation. The extrudability of gel formulation from the collapsible tube varied from $70-76 \mathrm{~g} / \mathrm{cm}^{2}$ where as the results of spreadability varies from 22 to $27 \mathrm{~g} . \mathrm{cm} / \mathrm{sec}$. A comparative study of viscosity and spreadability showed that the viscosity of the formulations increases, spreadability decreases and vice versa. From the results, it is clearly evident that all three optimized formulation showed good extrudability, homogenecity, viscocity and spreadability. The developed gel formulations were subjected to stability study as per ICH guidelines for the period of three months. By observing that effect of aging, viscosity, $\mathrm{pH}$, spreadability, extrudability, it was confirmed that the developed gel posses good stability. It was observed that slight phase separation of F2 occurring at $40^{\circ} \mathrm{C}$ temperature. Other formulations showed good stability. The $\mathrm{pH}$ was constant throughout the study to about 6.5 and the gel did not produce any irritation upon application to the skin. The drug content uniformity of the gels were found in the range of $82-92 \%, \mathrm{~F} 3$ formulation contain more drug content as compared to other two gel formulations. F3 shows greater drug release 57.2\% as compared with F2 drug release which is $56.2 \%$ in $5 \mathrm{hrs}$.

\section{CONCLUSION}

This research work is carried out to develop a new topical herbal gel formulation for topical application. The prepared herbal gel was further evaluated for $\mathrm{pH}$, Viscosity and extrudability, Spreadability, Drug content uniformity, In-vitro diffusion study, and stability Studies. The $\mathrm{pH}$ of all the formulations was in the range compatible with normal $\mathrm{pH}$ range of the skin. The drug content released was also above average. The rheological behaviors of the gel formulations were studied with Brookfield viscometer. The results indicated the viscosity of gel formulations was consistant neither too thick nor too thin. A comparative study of viscosity and Spreadability showed that with increase in viscosity of the formulation, the Spreadability decreased and vice versa. The gel formulation F3 was found to have all the desirable properties. Based on the above parameters, the formulation F3 is concluded as most promising formulation and in vitro model can be use for evaluation of its biological potency and it will useful for further clinical application.

\section{Reference:}

1. Diandian shen, Development of anti-inflammatory agents from the aromatic plants, Origanum spp. and Mentha spp., and analytical methods on the quality control of bioactive phenolic compounds, dissertation work, October, 2008; 2-3.

2. Abu Syed Md. Mosaddek, Md. Mamun Ur Rashid. Bangladesh J Pharmacology 2008; 3: 44 - 47.

3. . http://www.ayurvedaconsultants.com/herb consult.aspx?commonName=NIRGUNDI accessed on Nov 2010.

4. Sultana a., rahman k.u., padmaja a. R. And rahman s., Boswellia serrata roxb. A traditional herb with versatile pharmacological activity: a review , 2013; ijpsr, vol. 4(6): 2106-2117.

5. Garje K.L., Salunkhe K.S., Review on: anti-inflammatory herbal gel of Boswellia serrata \& Vitex negundo, 2013; IJPBS 3(2) : 41-49.

6. Singh A., Duggal S., Kaur N., Singh J., Berberine: Alkaloid with wide spectrum of pharmacological activities, 2010; Journal of Natural Products, 3: 64-75.

7. Gupta K., Sharma S., Khokra S., Sahu R., Jangde R., Evaluation of wound healing activity of crude extract of Vitex negudo on rats, Pharmacologyonline, 2012; 2: 1212-1216.

8. Khadabadi S.S., Deore S.L., Baviskar B.A., "Experimental phytopharmacognosy, A Comprehensive Guide. Nirali Prakashan, first edition, 2011: 5.6-5.7.

9. Pudke Vrushali k., Development and evaluation of antifungal herbal formulation for subcutaneous infection, dissertation submitted to Sant Gadge Baba Amravati university, Government college of Pharmacy Amravati, 2014; 75-82.

10. Gupta M, Verma PRP, Marwaha RK, Faruk A, Singh G. Formulation and evalution of meloxicam gel. J.Pharm.research 2008;7:27-31. 
Chavhan A. Sarin ${ }^{1}$, International Journal of Ayurvedic \& Herbal Medicine 7(4) July.-Aug. 2017 (2756-2762)

11. Jadhav KR, Shetye SL, Kadam VJ. Design and Evaluation of Microemulsion Based Drug DeliverySystem. International Journal of Advances in Pharmaceutical Sciences 2010; 1:156-166.

12. Wood JH, Catacalos G, Liberman SV. Adaptation of commercial viscometers for special applications in pharmaceutical rheology - Severs extrusion rheometer. J Pharm Sci 1963; 52:375378.

13. Singh Manish, Formulation and Evaluation of Herbal Gel containing Ethanolic Extract of Ipomoea Fistulosa, IJSR, July 2014; 3(7): 2319-7064.

14. ICH guidelines. Stability testing of new drug substances and products, Current step 4 version dated 6 February 2003.

15. (http://www.ich.org/fileadmin/Public_Web_Site/ICH_Products/Guidelines/Quality/Q1A_R2/Step4/ Q1A_R2_Guideline.pdf) 